\title{
Road Safety and Accident Reduction
}

\author{
M. Manikantan ${ }^{1}$, Dr. S. Siddiraju ${ }^{2}$ \\ ${ }^{1}$ P.G. Student, Siddharth Institute of Engineering \& Technology, Puttur-517583 \\ ${ }^{2}$ Professor, Siddharth Institute of Engineering \& Technology, Puttur-517583
}

\begin{abstract}
Now a days the accidents are occurring frequently due to the uncontrolled speed of vehicles. The accidents may occur due to the inefficiency of road geometric designs or reckless driving of vehicles or may be due to driving in drunken condition also. The human life is most valuable thing. Due to accidents, most of the human lives are last in death. To control these problems we need to take care of each and every point from inception to end of work. It is also necessary to maintain it properly after the construction. Road safety becomes a complex and multifaceted problem for the simple reason that transportation and development is becoming more intense and complicated than ever before. This is inturn due to population and economic activities growth in their size. Independent studies by both World Health Organization and World Bank have estimated that about 5,00,000 people lost their lives and over 15 million suffer injuries each year as a result of road accidents. In India the number of accidents and the fatalities has been increasing over the years and accidents per 1000 vehicles are high in India compared to other developed countries in the world. The tendency of accidents to cluster or concentrate at few spots is known as "Black spots" or "accident spots". Here we had selected the "Alankanpalli circle" as accident spots in kadapa, near A.P Tourism. We performed the traffic studies at this circle to redesign the rotary intersection and to check the sufficient weaving length, width at entry and exit, capacity of rotary, super elevation etc., The traffic studies consist of classified traffic volume count, spot speed studies, Inventory surveys etc. Finally we give the proper solution for the accidents reduction which are furnished in this project report clearly.
\end{abstract}

Keywords: Accident, Road Safety, Traffic Volume Count, Black Spots, Spot Speed

\section{General}

The objective of the present study is to identify the accident locations on highways radiating from Kadapa town. To conduct traffic surveys to collect traffic data and location features on these accident prone locations. To analyze the causative factors for accidents on these highways black spots and suggest accident countermeasures.

\section{Selection of Location}

The black spots are collected from R.T.O office kadapa. From these data we selected the following spots:

1) Alankanpalli circle near A.P. Tourism in kadapa,

In this project we have conducted the traffic surveys as follows:

a) Classified traffic volume count at Alankanpalli circle

b) Spot speed study at Gooty road near Alankanpalli circle

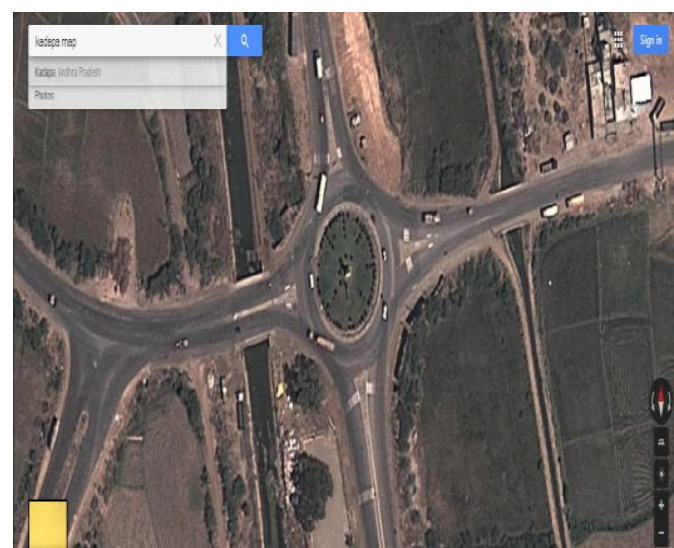

Figure 1: View of Alankanpalli circle, Kadapa

\section{Classified Traffic Volume Count}

Traffic volume is the number of vehicles crossing a section of road per unit time at any selected period. Counting of traffic volume can be done by Manual method and Mechanical counters. Here we prefer the Manual Count method.

The classified traffic volume count at Alankanpalli circle location in kadapa has been collected. The vehicles are classified into the following classes:

2-Wheeler (2W), 3-Wheeler (3W), Car/Jeep (other than taxi), Van/Mini Bus, Trucks (LCV: (Light Commercial Vehicle), 2-Axle, 3-Axle, Multi Axle, Bus, Cycle, Tractor.

The directional classified traffic volume is collected at peak hours as 8.00 AM-10.00 AM, 12.00 PM-2.00 PM, and 6.00 PM-8.00 PM in a day. The six hour volume count is carried out in a day and this has been conducted for 7 days continuously.

The traffic volume is converted into PCUs

PCU(Passenger Car Unit): Different classes of vehicles are found to use the common roadway facilities without segregation on most of the roads in developing countries like India. It is a common practice to consider the passenger car as the standard vehicle unit to convert the other vehicle classes and this unit is called Passenger Car Unit or PCU. The PCU conversion factor is taken from IRC

\section{Spot Speed Study}

Spot speed is the instantaneous speed of a vehicle at a specified section or location. We selected the straight stretch 


\section{International Journal of Science and Research (IJSR) \\ ISSN (Online): 2319-7064}

Index Copernicus Value (2013): 6.14 | Impact Factor (2015): 6.391

in Gooty road and performed the Spot speed Survey as per IRC recommendations.

\section{Road Inventories}

We performed the road inventories at Alankanpalli circle, P.P Kunta and D. Agraharam.

Table 1: Consolidated Spot Speed Data

\begin{tabular}{|c|c|}
\hline Sped Range & No. of vehicles observed \\
\hline $0-10$ & 7 \\
\hline $10-20$ & 6 \\
\hline $20-30$ & 6 \\
\hline $30-40$ & 69 \\
\hline $40-50$ & 73 \\
\hline $50-60$ & 35 \\
\hline $60-70$ & 21 \\
\hline $70-80$ & 10 \\
\hline $80-90$ & 9 \\
\hline $90-100$ & 2 \\
\hline $100-110$ & 2 \\
\hline
\end{tabular}

Table 2: Frequency Distribution of Spot Speed Data

\begin{tabular}{|c|c|c|c|c|}
\hline $\begin{array}{c}\text { Speed } \\
\text { Kange } \\
\text { Kmph }\end{array}$ & $\begin{array}{c}\text { Mid } \\
\text { speed }\end{array}$ & $\begin{array}{c}\text { Frequency, } \\
\text { f }\end{array}$ & $\begin{array}{c}\text { Frequency, } \\
\%\end{array}$ & $\begin{array}{c}\text { Cummulative } \\
\text { frequency, \% }\end{array}$ \\
\hline $0-10$ & 5 & 7 & 2.92 & 2.92 \\
\hline $20-$-Oct & 15 & 6 & 2.5 & 5.42 \\
\hline $20-30$ & 25 & 6 & 2.5 & 7.92 \\
\hline $30-40$ & 35 & 69 & 28.75 & 36.67 \\
\hline $40-50$ & 45 & 73 & 30.42 & 67.09 \\
\hline $50-60$ & 55 & 35 & 14.58 & 81.67 \\
\hline $60-70$ & 65 & 21 & 8.75 & 90.42 \\
\hline $70-80$ & 75 & 10 & 4.17 & 94.59 \\
\hline $80-90$ & 85 & 9 & 3.75 & 98.34 \\
\hline $90-100$ & 95 & 2 & 0.83 & 99.17 \\
\hline $100-110$ & 105 & 2 & 0.83 & 100 \\
\hline & & 240 & 100 & \\
\hline
\end{tabular}

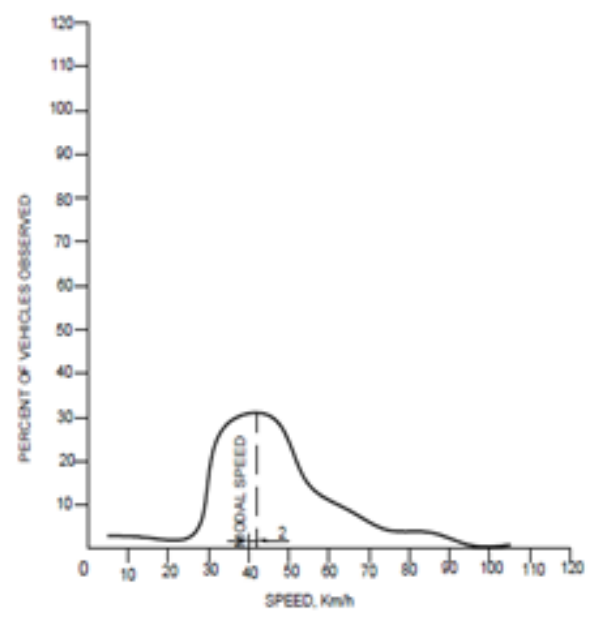

Frequency Distribution Curve of the Spot Speeds

Figure 2: Frequency Distribution Curve of the Spot Speeds Modal speed $=42 \mathrm{Kmph}$

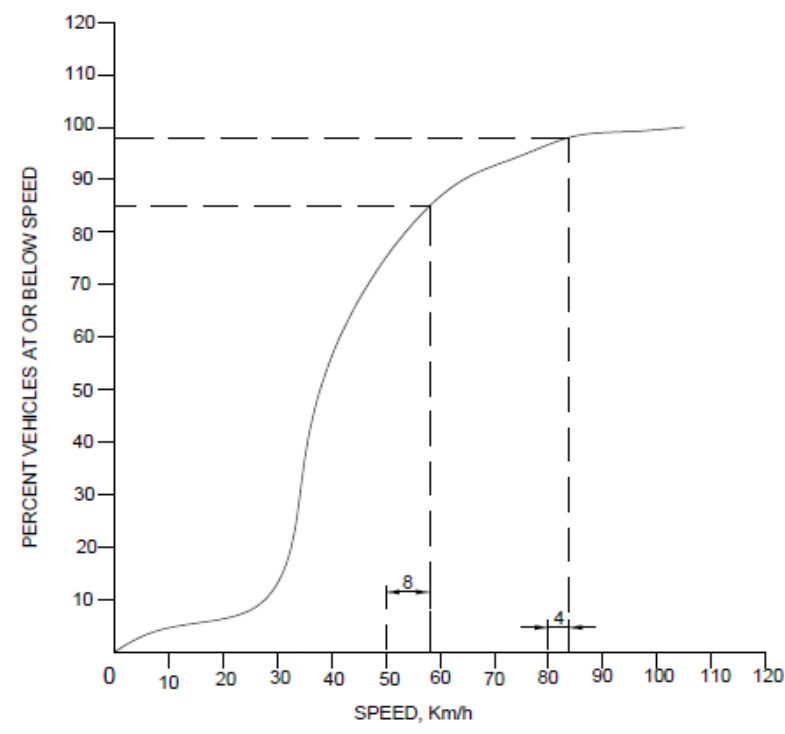

Cumulative Speed Distribution

Figure 3: Cumulative Speed Distribution

Upper speed limit $=58 \mathrm{Kmph}$

Lower speed limit $=32 \mathrm{Kmph}$

Speed to check design element $=84 \mathrm{Kmph}$

\section{Design and Comparison of Rotary Intersection}

\section{Design of Rotary Intersection}

Obtained PCU's from collected data:

The traffic flows at Alankanpalli circle intersection of two highways are given below:

Table 3: Total PCUs per Hour

\begin{tabular}{|c|c|c|c|}
\hline \multirow{2}{*}{ Approach } & \multicolumn{3}{|c|}{ Total PCU's per Hour } \\
\cline { 2 - 4 } & Left turning & Straight ahead & Right turning \\
\hline Chennai & 115 & 169 & 125 \\
\hline Kurnool & 146 & 321 & 124 \\
\hline Gooty & 102 & 175 & 265 \\
\hline Kadapa & 209 & 349 & 99 \\
\hline
\end{tabular}

The highways at present intersect at right angles and have a carriageway width of $15 \mathrm{~m}$. We need to design a rotary intersection making suitable assumptions.

The rotary is located in an urban section and hence a design speed of 30 K.P.H. is appropriate. Since the intersection legs carry almost equal traffic, a round-shaped central island will be adopted. The entrance and exit angles will be $45^{\circ}$ each. A radius of $20 \mathrm{~m}$ at entry, $40 \mathrm{~m}$ at exit and $20 \mathrm{~m}$ for the central island will be adopted. These values conform to Indian standards.

The traffic in terms of PCU's from each leg is depicted in below Fig.4.1 


\section{International Journal of Science and Research (IJSR) \\ ISSN (Online): 2319-7064}

Index Copernicus Value (2013): 6.14 | Impact Factor (2015): 6.391

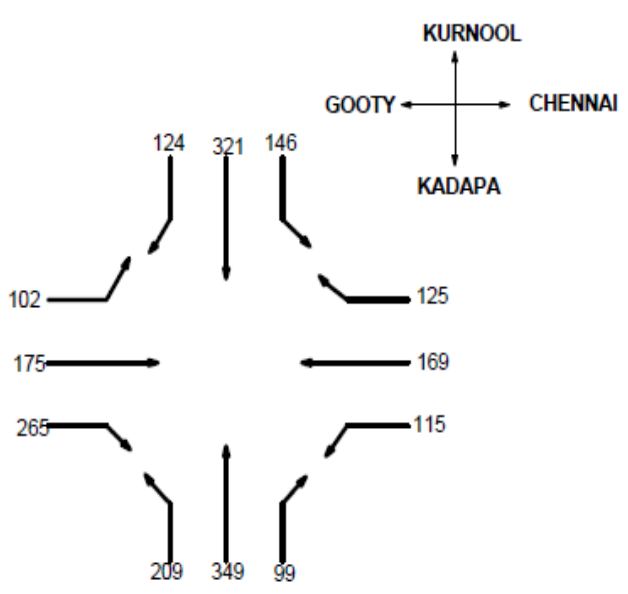

Figure 4: PCUs of each direction

The traffic in terms of PCUs on each leg is depicted in Fig.4.2

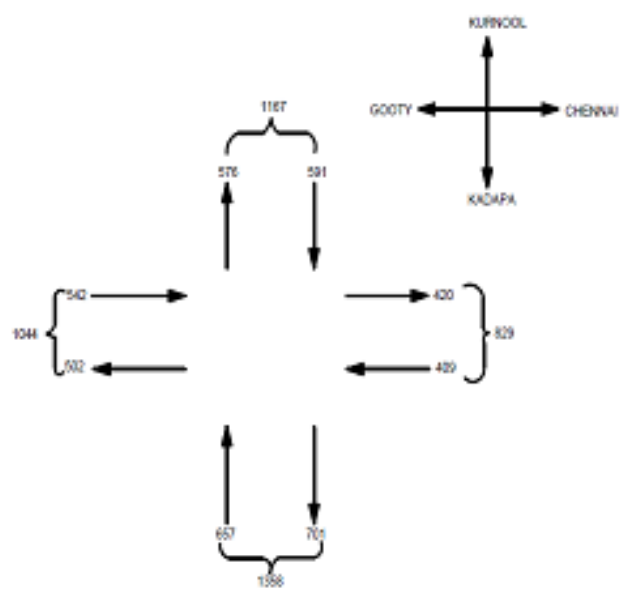

Figure 5: PCUs of each leg

The traffic is assigned to the network in Fig.4.3

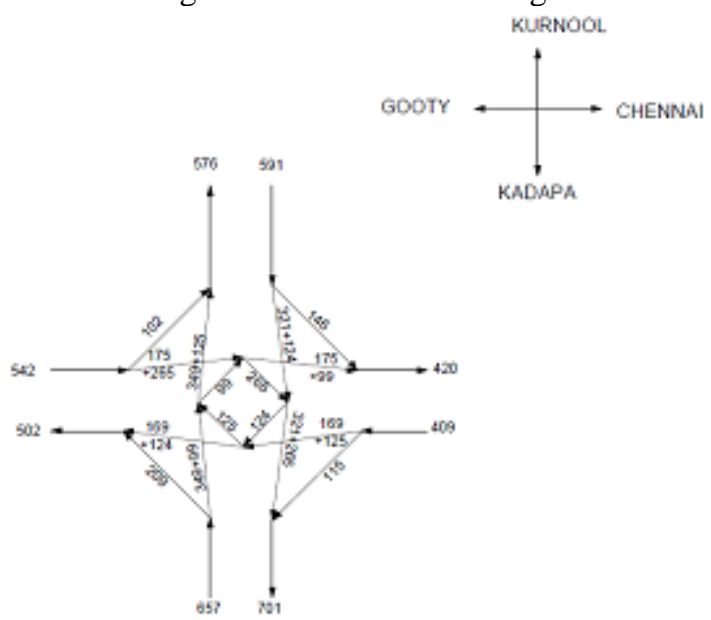

Figure 6: Weaving network

The maximum 2-way flow in the intersection leg (towards kadapa) is 1358 PCUs/hour, and the maximum in one direction is 701 PCUs/hour. From Table:4.1 a 4-lane road with moderate interference from cross-traffic has capacity of 1400-1800 PCU/hour in one direction.
Table 4: Design capacities for Arterial streets and Urban highways

\begin{tabular}{|c|c|c|}
\hline $\begin{array}{ll}\text { S. } \\
\text { No } \\
\end{array}$ & Type of highway & $\begin{array}{c}\text { Design capacity (passenger } \\
\text { cars per hour per } 3.65 \mathrm{~m} \text { lane) }\end{array}$ \\
\hline 1 & $\begin{array}{l}\text { Major suburban highway with } \\
\text { moderate interference from } \\
\text { cross-traffic and road sides, } \\
\text { level of service C. }\end{array}$ & $700-900$ \\
\hline 2 & \begin{tabular}{|c|} 
Major suburban highway, \\
considerable interference from \\
cross-traffic and road sides, \\
level of service C.
\end{tabular} & $500-700$ \\
\hline 3 & \begin{tabular}{|c|} 
Arterial street, traffic signals \\
average 1.6 K.M. or more apart, \\
parking prohibited and refuge \\
provided for stalled vehicles, \\
level of service C. \\
\end{tabular} & $400-600$ \\
\hline 4 & $\begin{array}{l}\text { Arterial street, traffic signals } \\
\text { average less than } 1.6 \mathrm{~K} . \mathrm{M} . \\
\text { apart, parking prohibited. }\end{array}$ & $\begin{array}{l}\text { As governed by capacity of } \\
\text { critical intersections }\end{array}$ \\
\hline
\end{tabular}

The width of carriageway at entry and exit may be taken from Table 5 given below.

Table 5: Width of carriageway at entrance and exit

\begin{tabular}{|c|c|c|}
\hline $\begin{array}{l}\text { Carriageway width of } \\
\text { approach road }\end{array}$ & $\begin{array}{l}\text { Radius at } \\
\text { entry }(\mathrm{m})\end{array}$ & $\begin{array}{l}\text { Width of carriageway at } \\
\text { entry and exit }(\mathrm{m})\end{array}$ \\
\hline $7 \mathrm{~m}$ (2 lanes) & \multirow{4}{*}{$25-35$} & 6.5 \\
\hline $10.5 \mathrm{~m}$ (3 lanes) & & 7.0 \\
\hline $14 \mathrm{~m}$ (4 lanes) & & 8.0 \\
\hline $21 \mathrm{~m}$ (6 lanes) & & 13.0 \\
\hline $7 \mathrm{~m}$ (2 lanes) & \multirow{4}{*}{$15-25$} & 7.0 \\
\hline $10.5 \mathrm{~m}$ (3 lanes) & & 7.5 \\
\hline $14 \mathrm{~m}$ (4 lanes) & & 10.0 \\
\hline $21 \mathrm{~m}$ (6 lanes) & & 15.0 \\
\hline
\end{tabular}

For a 4-lane road, a width of $10.0 \mathrm{~m}$ is in order. The width of the non-weaving section is also kept $10.0 \mathrm{~m}$. The width of the weaving section is,

$w=\frac{e_{1}+e_{2}}{2}+3.5$

$$
=\frac{10+10^{2}}{2}+3.5=13.5 \mathrm{~m}
$$

The minimum length of the weaving section should be $30 \mathrm{~m}$ from Table:4.3 but this fails the requirement that the ratio $\frac{l}{w}$ should be at least 4 . So adopt $55 \mathrm{~m}$, which gives a $\frac{l}{w}$ ratio slightly greater than 4 .

Table 6: Minimum length of weaving section

\begin{tabular}{|c|c|}
\hline Design Speed (K.P.H) & Minimum wearing length (m) \\
\hline 40 & 45 \\
\hline 30 & 30 \\
\hline
\end{tabular}

The maximum weaving occurs in the CHENNAI-KADAPA section.

\section{$p=\frac{586+294}{124+586+294+115}=0.79$}

Where, $p=$ Proportion of weaving traffic, i.e. ratio of sum of crossing streams to the total traffic on the weaving section.

$$
=\frac{b+c}{a+b+c+d}
$$

\section{Volume 5 Issue 6, June 2016 www.ijsr.net}




\section{International Journal of Science and Research (IJSR) \\ ISSN (Online): 2319-7064}

Index Copernicus Value (2013): 6.14 | Impact Factor (2015): 6.391

Capacity of rotary $Q_{p}=\frac{280 \mathrm{w}\left(1+\frac{Q}{W}\right)\left(1-\frac{p}{g}\right)}{1+\frac{W}{I}} \quad$ where, $Q_{p}=$ practical capacity of the weaving section of the rotary in passenger car units , (PCUs per hour).

$\mathrm{W}=$ width of the weaving section in meters (within the range of $6-18 \mathrm{~m}$ ).

$\mathrm{e}=$ average entry width of the rotary in meters.

$$
=\frac{e_{1}+e_{2}}{2}
$$

$l=$ length of weaving section between the ends of the channelizing islands in meters

$p=$ Proportion of weaving traffic, i.e. ratio of sum of crossing streams to the total traffic on the weaving section.

$$
=\frac{b+c}{a+b+c+d}
$$

Therefore the Capacity of rotary ,

$$
Q_{p}=\frac{280 \times 13.5\left(1+\frac{10}{18.5}\right)\left(1-\frac{0.59}{8}\right)}{1+\frac{18.5}{5.5}}
$$

$$
=3892 \mathrm{PCU} / \mathrm{hour} \text {. }
$$

This is very much higher than the traffic flow of 1358 PCU/hour.

A sketch of the junction is given in below fig. 4.4

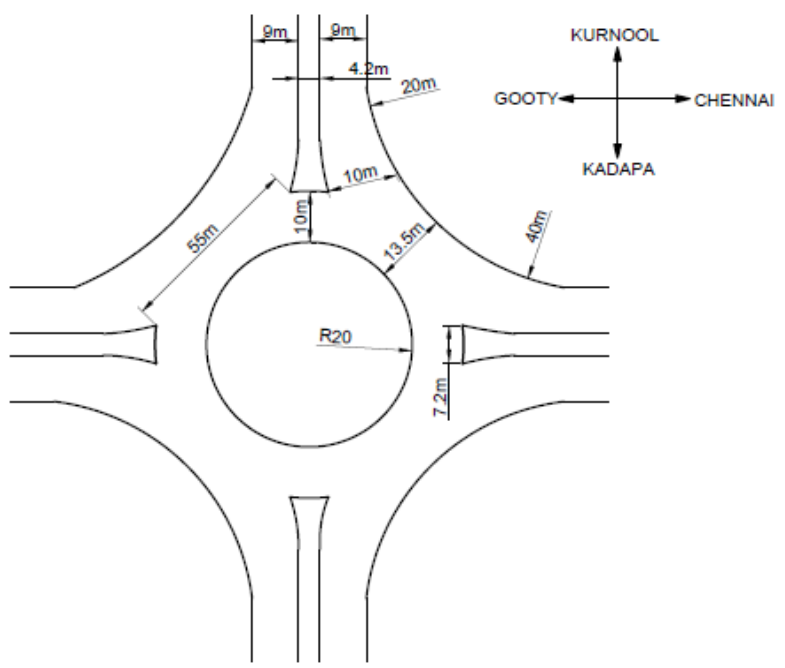

Figure 7: Designed Rotary intersection

Explaination:

- For 2 lane road the range of PCUs shall be 1400-1800. But we got only 701 PCUs, hence it is safe.

- We consider that the width at entry and exit is $10 \mathrm{~m}$. But $>10 \mathrm{~m}$ width at entry and exit is existing in field. Hence safe.

- We got width of weaving section in design is $13.5 \mathrm{~m}$. But in the site it is only $10.7 \mathrm{~m}$. So we need to take care of this.

- From design the length of weaving section obtained is 55 $\mathrm{m}$. At site only $40 \mathrm{~m}$ length is exist. It should satisfy the condition of the $1 / \mathrm{w}$ ratio should be at least 4 . We should take care of this as increasing the length of weaving section.

- Super elevation should be 0.07 as per IRC 65-1976. At the site it is not properly exist. It vary from 0.04 to 0.08 . It leads inconvenience to the weaving traffic.
Table 7: Comparison between designed and existing section

\begin{tabular}{|c|c|c|c|}
\hline Items & $\begin{array}{c}\text { Design } \\
\text { Section }\end{array}$ & $\begin{array}{c}\text { Existing } \\
\text { section }\end{array}$ & $\begin{array}{c}\text { Range as per IRC 65- } \\
1976\end{array}$ \\
\hline PCUs & 701 & - & $1400-1800$ \\
\hline Width at entry and exit & $10 \mathrm{~m}$ & $>10 \mathrm{~m}$ & $10 \mathrm{~m}$ for 4-lane \\
\hline $\begin{array}{c}\text { Width of weaving } \\
\text { section }\end{array}$ & $13.5 \mathrm{~m}$ & $10.7 \mathrm{~m}$ & $13.5 \mathrm{~m}$ by formula \\
\hline $\begin{array}{c}\text { Length of weaving } \\
\text { section }\end{array}$ & $55 \mathrm{~m}$ & $40 \mathrm{~m}$ & $\begin{array}{c}\text { The } 1 / \mathrm{w} \text { ratio should } \\
\text { be at least 4 }\end{array}$ \\
\hline $\begin{array}{c}\text { Super elevation } \\
\text { sumph }\end{array}$ & 0.07 & $0.04-0.08$ & 0.07 for 30-40 Kmph \\
speed
\end{tabular}

\section{Conclusion}

\section{Reasons for accidents}

- Collision between vehicles due to misunderstanding, defect in weaving length and road surface.

- Absence of Road signs like warning signs, Road markings etc.

- Uneven approach of shoulders near the section

- Lighting at night times

- Driving in drunken condition

\section{Solution:}

- Modifying the length of weaving section.

- Alter the surface of the road at entry and exit of rotary.

- Introducing the Road signs and markings.

- Maintaining the proper super elevation and shoulders.

- Providing lightings at night.

\section{References}

[1] Highway Engineering by S.K.Khanna, C.E.G.Justo.

[2] Traffic Engineering and Transport planning by Dr. L.R. Kadiyali.

[3] Principles and Practices of Highway Engineering (Including Expressways and Airport Engineering) by Dr. L.R. Kadyali, Dr. N.B. Lal.

[4] IRC 67-2010 Code of practice for road signs.

[5] IRC:SP:19-2001 Manual for survey, investigation and preparation of road projects.

[6] IRC:65-1976 Recommended practice for traffic rotaries.

[7] http://hdl.handle.net/2429/9091

[8] www.fpz.unizg.hr/traffic

[9] International Journal of Chemical, Environmental \& Biological Sciences (IJCEBS)

Volume 1, Issue 2 (2013) ISSN $2320-4087$ (Online)

[10] www.isaet.org 